\title{
Article \\ Effects of Water Removal from Palm Oil Reactant by Electrolysis on the Fuel Properties of Biodiesel
}

\author{
Cherng-Yuan Lin *(i) and Lei Ma
}

check for updates

Citation: Lin, C.-Y.; Ma, L. Effects of Water Removal from Palm Oil Reactant by Electrolysis on the Fuel Properties of Biodiesel. Processes 2022, 10, 115. https://doi.org/10.3390/ pr10010115

Academic Editor:

Chiing-Chang Chen

Received: 13 December 2021

Accepted: 4 January 2022

Published: 6 January 2022

Publisher's Note: MDPI stays neutral with regard to jurisdictional claims in published maps and institutional affiliations.

Copyright: (C) 2022 by the authors. Licensee MDPI, Basel, Switzerland. This article is an open access article distributed under the terms and conditions of the Creative Commons Attribution (CC BY) license (https:// creativecommons.org/licenses/by/ $4.0 /)$

\author{
Department of Marine Engineering, National Taiwan Ocean University, Keelung 202, Taiwan; \\ awpcsawp@yahoo.com.tw \\ * Correspondence: Lin7108@ntou.edu.tw; Tel./Fax: +886-2-2462-2307
}

\begin{abstract}
Biodiesel, which is composed of mono-alkyl esters of long carbon-chained fatty acids, is used as an alternative fuel to petro-diesel. The water content of the reactant mixture of feedstock oil influences the extent of transesterification and thus the fuel characteristics. Lower water content in feedstock oil is generally suggested for successful transesterification. This experimental study removed water from the reactant mixture of feedstock palm oil and methanol during transesterification using various systems composed of either electrodes or molecular sieves with rotary vibration. The effect of input electrical energy, number of electrodes, vibration modes, and operating time on the amount of water removed from the reactant mixture and the fuel properties of the final biodiesel product were analyzed and compared with those achieved using molecular sieves. The results show that the biodiesel—after water was removed during transesterification-appeared to have increased kinematic viscosity, cetane index, distillation temperature, and acid value, while the heating value, flash point, ignition point, and water content decreased with an increase in the input electrical energy of the electrodes responsible for electrolyzing water away. Electrolysis by the double-pair electrodes was more effective at reducing acid value and water content than that performed by the single-pair electrodes under the same input electrical energy. The biodiesel was found to have the lowest water content $(0.0304 \mathrm{wt} . \%)$ and the highest water-removal rate $(0.011 \mathrm{wt} . \%)$ when water was removed during transesterification by the double-pair electrodes with an input electrical energy of $9 \mathrm{~J} /(\mathrm{g}$ palm oil). The water-removal rate of the rotary-vibrating molecular sieves was 11.24 times that of the single-pair electrodes. The biodiesel was found to have increased kinematic viscosity with higher input electrical energy, reaching $5.15 \mathrm{~mm}^{2} / \mathrm{s}$ when the double-pair electrodes with an input electrical energy of $11 \mathrm{~J} /$ (g palm oil) were used. Longer carbon-chained fatty acids, ranging from C20 to C24, amounted to $0.74 \mathrm{wt} . \%$ of the biodiesel produced using the double-pair electrodes, which was greater than that seen for the single-pair electrodes. However, the molecular sieve method consumed more energy than the double-pair electrodes did to remove the same amount of water from the palm oil reactant mixture via transesterification.
\end{abstract}

Keywords: water removal; molecular sieve; electrode structure; transesterification; palm-oil biodiesel

\section{Introduction}

Biodiesel, also termed fatty acid methyl esters (FAME) or fatty acid ethyl esters (FAEE), is primarily composed of mono-alkyl esters of long carbon-chained fatty acids. Biodiesel is used as an alternative fuel to petro-derived diesel to alleviate gaseous and particulate matter emissions and to mitigate the extent of the greenhouse effect [1]. The fuel properties of biodiesel are regulated by ASTM D6751 and EN 14214 specifications to preserve the performance of combustion equipment and protect the environment from destruction due to emissions from fuel burning [2]. The existence of water in the biodiesel product influences combustion to various extents and is thus considered one of the dominant fuel characteristics. The corrosion rate of the metallic materials of an engine may be accelerated with higher water content in the biodiesel fuel. The blending of water with fuel thus results 
in the phenomenon of fuel emulsion and saponification, leading to blockage of the fuel pumping system and even engine breakdown [3]. It is thus recommended to use feedstock oil with as low a water content as possible to prevent a reduced conversion rate through the transesterification reaction for biodiesel production. Water content, free fatty acids (FFA), and acid value should be lower than $0.06 \mathrm{wt} . \%, 0.5 \mathrm{wt} . \%$, and $1 \mathrm{mg} \mathrm{KOH} /(\mathrm{g}$ oil), respectively, in order to achieve successful transesterification of feedstock oil [4]

Ma and Hanna [5] found that the existence of water in raw feedstock oil might reduce the conversion rate of FAME and lead to the saponification phenomenon during transesterification reactions. They thus suggested that low water content in raw oil is required to achieve a high yield of FAME. The production rate of biodiesel can reach above $90 \%$ if the water content is kept as low as $0.05 \mathrm{wt} . \%$ [6,7]. The biodiesel yield from transesterification - when enhanced by a strong acidic catalyst - was found to be influenced much less by the existence of free fatty acids (FFA) and water in the feedstock oil [8] than in that enhanced by a strong alkaline catalyst. Some studies $[9,10]$ considered that a highly anhydrous reactant mixture is required during a strong alkaline-catalyst transesterification reaction in order to produce biodiesel with a high ester content.

Electrolysis is a kind of non-spontaneous redox reaction that occurs under the compulsion of an external voltage [11]. The most common example of an electrolytic reaction is electrolysis of water molecules. Hydrogen bubbles appear at the cathode when oxygen bubbles are formed at the anode during the water electrolysis process [12,13]. Electrolysis is widely applied in the treatment of wastewater. Millet et al. [14] noted that ohmic resistance is frequently established due to corrosion of the electrode surface material, which results in deteriorating electron conduction. However, reactant mixture interfaces might be heated by the thermal energy produced by ohmic resistance during the electrolytic process, leading to enhancement of electrochemical reactions. Camacho et al. [15] applied a water-electrolytic reaction to produce hydrogen, which was then used to carry out hydrogen addition to a fuel reaction.

Electrical energy has been applied to electrolytically dissociate water molecules in an electrolyte so as to form hydrogen and oxygen molecules. Hu et al. [16] showed that the electrolytic efficiency of methanol is higher than that of water. Pre-mixing an alkaline catalyst such as sodium methoxide or potassium hydroxide with methanol is prone to forming water during transesterification with a strong alkaline catalyst. Raw vegetable oil and animal fat are also apt to absorb water from the environment during the storage period or the production process of biodiesel. Excess water content in the reactant mixture has been widely proven to retard the conversion rate of biodiesel from feedstock oil and worsen the properties of fatty acid methyl esters [17]. The application of continuous electric field onto the reactant mixture during the transesterification reaction could inhibit water formation and even electrolyze away pre-existing water molecules in the mixture during transesterification. In addition, many kinds of ions-such as alkoxide, triglyceride, hydroxides, etc. - may be produced through the electrolytic reaction, and the applied electric field could enhance the active movement and reaction of those ions [18]. $\mathrm{H}^{+}$and $\mathrm{OH}^{-}$ions are chemically bonded in the water molecule, in which their bond energy is generally weaker than the covalent bonds of organic compounds [19]. Hence, water molecules are more likely to be electrolytically dissociated when an electric field is applied to the reactant mixture.

Removing water from the raw oil or alcohol of the reactant mixture via evaporation is common [20] during transesterification reactions. However, biodiesel properties are apt to deteriorate under high-temperature heating of the reactant mixture. Hence, electrolysis was instead considered to remove water from feedstock oil. This study first experimentally investigated the effects of electrolytic dissociation of water from palm oil on the fuel properties of the biodiesel product. In addition, the water-removal efficiency and biodiesel properties after water removal from the feedstock oil mixture by electrolysis were compared with those achieved by molecular sieves with vibrating rotation. 


\section{Experiment Details}

Electrolysis was applied to continuously remove water from raw palm oil during the transesterification reaction step of biodiesel production. The effects of the number of electrodes and the input electrical energy of electrodes on the fuel properties of the biodiesel product were analyzed and compared with the fuel properties of biodiesel with water removed from the feedstock oil using molecular sieves with vibrating rotation.

\subsection{Arrangement of Electrodes and Reactant Mixture}

The electrodes for removing water were made of SUS 304 stainless steel. The dimensions of the electrodes were: $100 \mathrm{~mm}$ long, $12 \mathrm{~mm}$ wide, and $0.5 \mathrm{~mm}$ thick. There were 35 parallel meshes on the electrode surface. Each mesh dimension was $1 \mathrm{~mm} \times 6 \mathrm{~mm}$. The effective areas of the single-pair electrodes and the double-pair electrodes were $1980 \mathrm{~mm}^{2}$ and $3960 \mathrm{~mm}^{2}$, respectively. The input electrical energy, initially supplied by AC current, was converted to DC current by a power supply (model ADC 100-5, All Power Electronic Co. Ltd., New Taipei City, Taiwan) before being provided to the electrodes. The electric current supplied by the converter was measured by a universal electric meter (Model MT-1210, ProKit's Industries Co. Ltd., New Taipei City, Taiwan).

The electrochemical method was applied to dissociate water in the feedstock oil mixture. A beaker was filled with the reactant mixture of palm oil, the strong alkaline catalyst $\mathrm{NaOH}$, and methanol: Methanol and palm oil with a molar ratio of 9:1 and $\mathrm{NaOH}$ (1 wt.\% of palm oil) were added together to carry out the transesterification reaction. The single- or double-pair electrodes were placed in the liquid mixture within the beaker to remove water from the reactant mixture using a continuous input of electrical energy. The experimental layout of the equipment is illustrated in Figure 1. Figure 2 shows the arrangement of the electrodes and the direction of movement of electrical charge from a top-down view of the beaker containing the reactant mixture and electrodes.

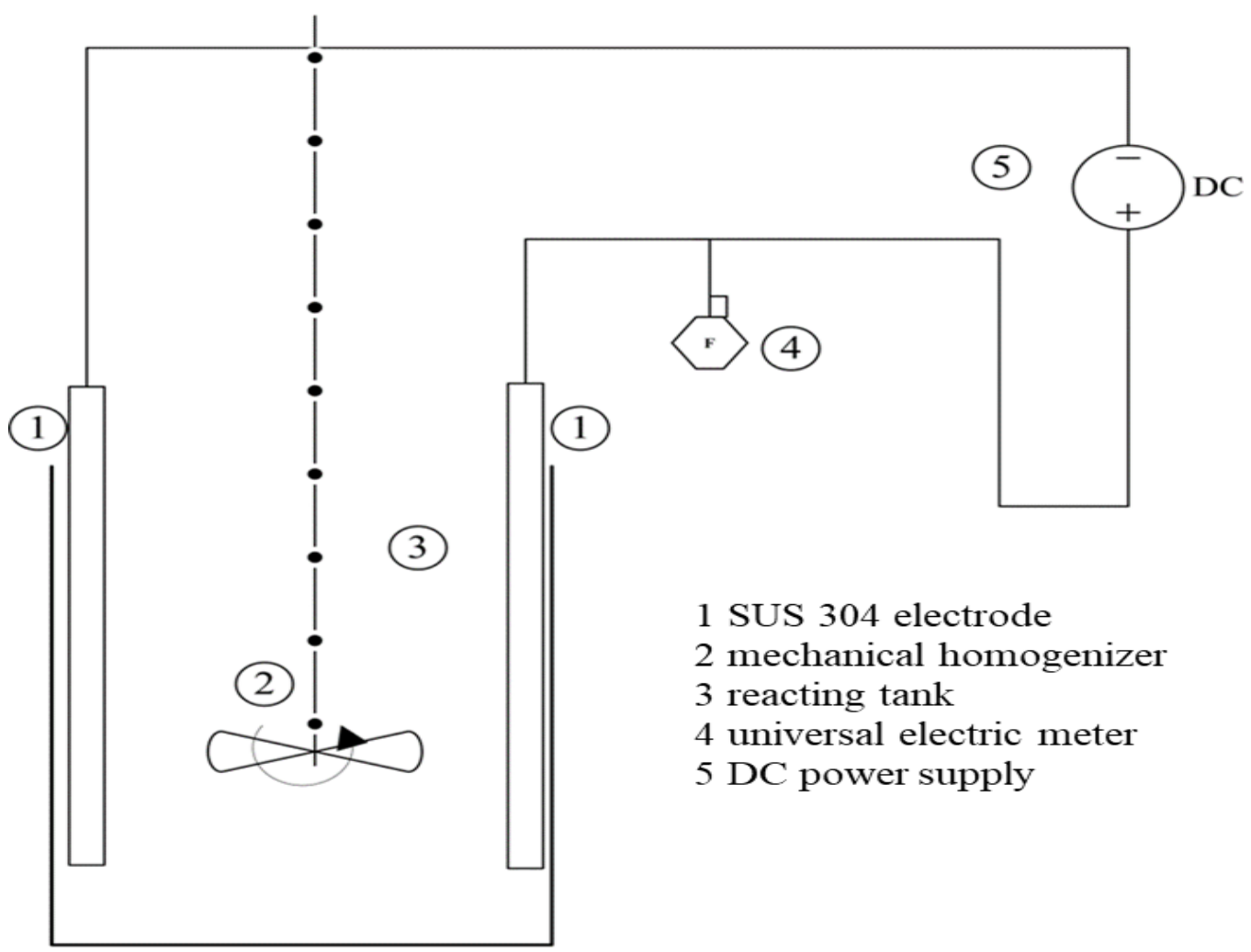

Figure 1. Experimental layout of water removal from reactant mixture by electrolytic dissociation during transesterification for biodiesel production. 


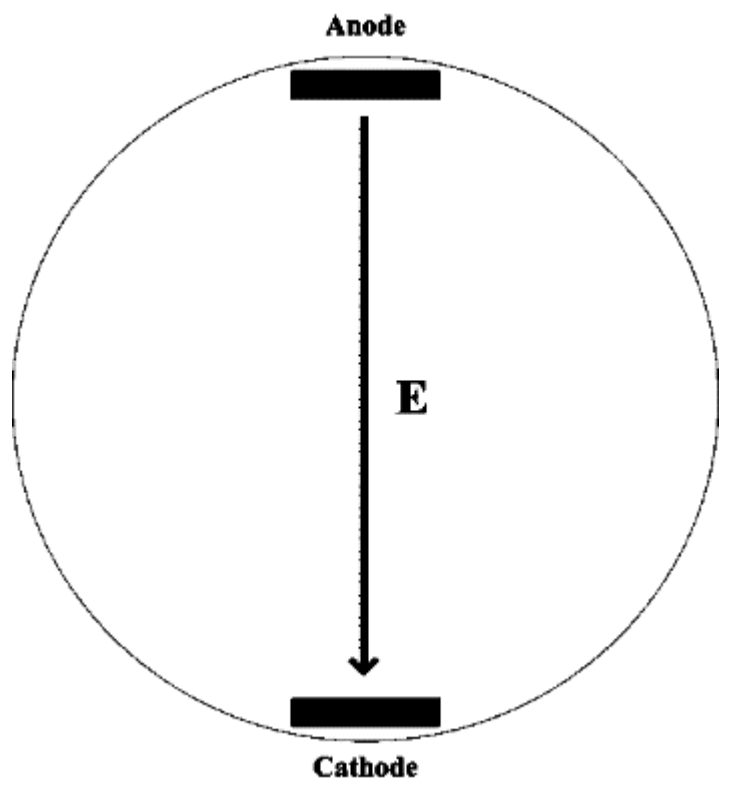

(a) Single-pair electrodes

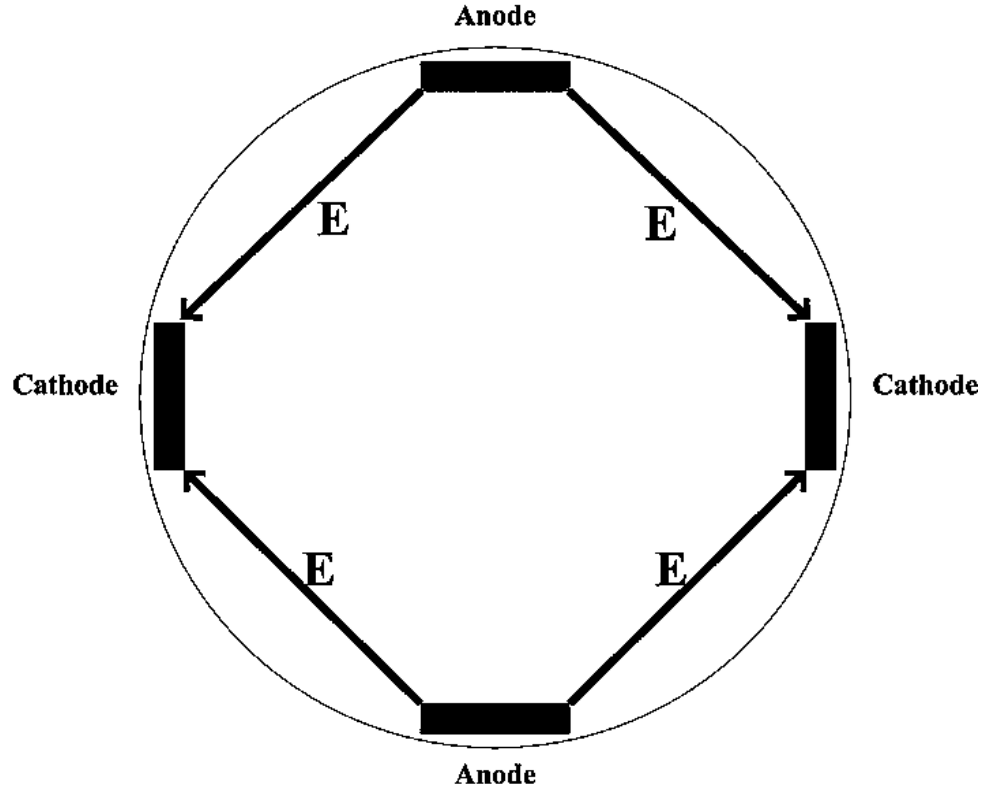

(b) Double-pair electrodes

Figure 2. Top-down view of the electrode arrangement for (a) single- and (b) double-pair electrodes, and the direction of movement of electrical charge within the beaker containing the palm oil mixture.

\subsection{Preparation of Biodiesel Samples}

The procedures for preparing the biodiesel products for further analysis of their fuel properties are described below. Methanol and the strong alkaline catalyst $\mathrm{NaOH}$ were pre-mixed for $10 \mathrm{~min}$ and poured into a beaker. Palm oil was pre-heated to $60^{\circ} \mathrm{C}$ and stirred into the mixture of catalyst and methanol using a mechanical homogenizer (model T50, Ika Inc., Staufen, Germany) in the beaker, which had been fitted with single- or double-pair electrodes. Input electrical energy of between 0 and $9 \mathrm{~J} /(\mathrm{g}$ palm oil) was provided and controlled by a DC power supply together with a universal electric meter. The reactant mixture was agitated by the mechanical homogenizer at a speed of $6000 \mathrm{rpm}$ to allow the transesterification reaction to proceed for $30 \mathrm{~min}$. At the same time, the water content was electrolytically dissociated by the electrodes. An adequate amount of glacial acetic acid was thereafter added to neutralize the crude biodiesel and glycerol. The crude mixture of biodiesel and glycerol was then separated by virtue of their gravity difference, with biodiesel in the upper layer. The separated biodiesel was heated at $70{ }^{\circ} \mathrm{C}$ for $30 \mathrm{~min}$ to vaporize away any unreacted methanol and any other volatile impurities. Deionized water (10 wt.\%) was added to the crude biodiesel several times to water wash it. The biodiesel was thereafter heated to $110{ }^{\circ} \mathrm{C}$ to remove water, unreacted compounds, and impurities, thus obtaining the fuel sample for further property analysis.

\subsection{Analysis of Fuel Properties}

The fatty acid compositions of the biodiesels, after being water-electrolyzed by singleor double-pair electrodes and washed by deionized water, were analyzed by gas-liquid chromatography (model Trace GC 2000, ThermoQuest Co., Markham, ON, Canada). The acid value of the biodiesel sample (in $\mathrm{mg} \mathrm{KOH} /(\mathrm{g}$ oil)) was determined by titrating $0.01 \mathrm{~N}$ potassium hydroxide $(\mathrm{KOH})$ into the mixture of the sample and the chemical reagent until the a pink color was produced. A volumetric Karl Fischer titration (model DL31, Mettler Toledo Ltd., Greifensee, Switzerland) used a Karl Fischer solution of sodium compound to titrate the biodiesel sample for analysis of the water content. The moisture content value was determined once the first trace of excess iodine appeared. A hydrometer arranged within a graduated cylinder was used to analyze the specific gravity of the biodiesel sample stored inside the cylinder. An oxygen bomb calorimeter (model 1261 
(automatically adiabatic), Parr Ltd., Moline, IL, USA) was used to determine the heating value of the fuel sample, which is defined as the amount of heat released by complete combustion, per kg of tested fuel. A capillary viscometer (model 50 123/IIc, Schott Gerate Ltd., Mullheim, Germany) was placed inside a water tank to measure the kinematic viscosity in centistokes (cSt) or, equivalently, $\mathrm{mm}^{2} / \mathrm{s}$ at a constant temperature of $40^{\circ} \mathrm{C}$. A PenskyMarten closed-cup flash point tester based on the ISO 3679:2015 standard method [21] was used to measure the flash point. The temperature of the fuel sample at the time of flash was recorded as the ignition point.

A distillation temperature analyzer (model HAD-620, Petroleum Analyzer Ltd., Houston, TX, USA) was used to analyze the distillation temperatures of the fuel samples. The first liquid drop was distilled, condensed, and collected through the distillation temperature analyzer and recorded as the distillation temperature of the initial boiling point (i.e., $\mathrm{T}_{\mathrm{IBP}}$ ), while 50 vol.\% liquid fuel was distilled, condensed, and collected and denoted as $\mathrm{T}_{50}$. An ASTM D86 curve was plotted to connect the distillation temperature data corresponding to the various volumetric percentages being distilled and condensed. The cetane index (CI), which represents the ignition quality of the diesel fuel used in a compression-ignition engine, was calculated using the specific gravity $(\mathrm{sg})$ and $\mathrm{T}_{50}$ of liquid sample fuel based on the following formula [22]:

$$
\begin{gathered}
C I=-420.34+0.016 A P I^{2}+0.192\left(\log T_{50}\right)+65.01\left(\log T_{50}\right)^{2}-0.0001809\left(T_{50}\right)^{2} \\
\text { where } A P I=141.5 / s g-131.5
\end{gathered}
$$

\section{Results and Discussion}

Electrolysis was applied to remove water from feedstock palm oil and ethanol during transesterification reactions. The effects of the number of electrodes and input electrical energy on the water-removal efficiency and the fuel properties of the resultant biodiesel products were experimentally investigated. The experimental uncertainties of the acid value, water content, heating value, kinematic viscosity, specific gravity, flash point, ignition point, and distillation temperature are $\pm 2.59, \pm 1.82, \pm 3.17, \pm 2.24, \pm 1.36, \pm 2.73, \pm 2.41$, and \pm 2.68 , respectively. The results are explained and discussed below.

\subsection{Acid Value and Moisture Content}

The biodiesel with water removal by single-pair electrodes during transesterification was shown to have a significantly higher acid value than that produced by double-pair electrodes, as seen in Figure 3. The acid values of the biodiesel samples increased with the increase in input electrical energy. The biodiesel without water removal by electrodes was observed to have an acid value of $1.28 \mathrm{mg} \mathrm{KOH} /(\mathrm{g}$ oil), which was approximately between the values of the biodiesels with water removal by single- and double-pair electrodes. The acid value of the biodiesel with water removed by double-pair electrodes tended to increase slightly with an input electrical energy greater than $7 \mathrm{~J} /$ (g palm oil). 


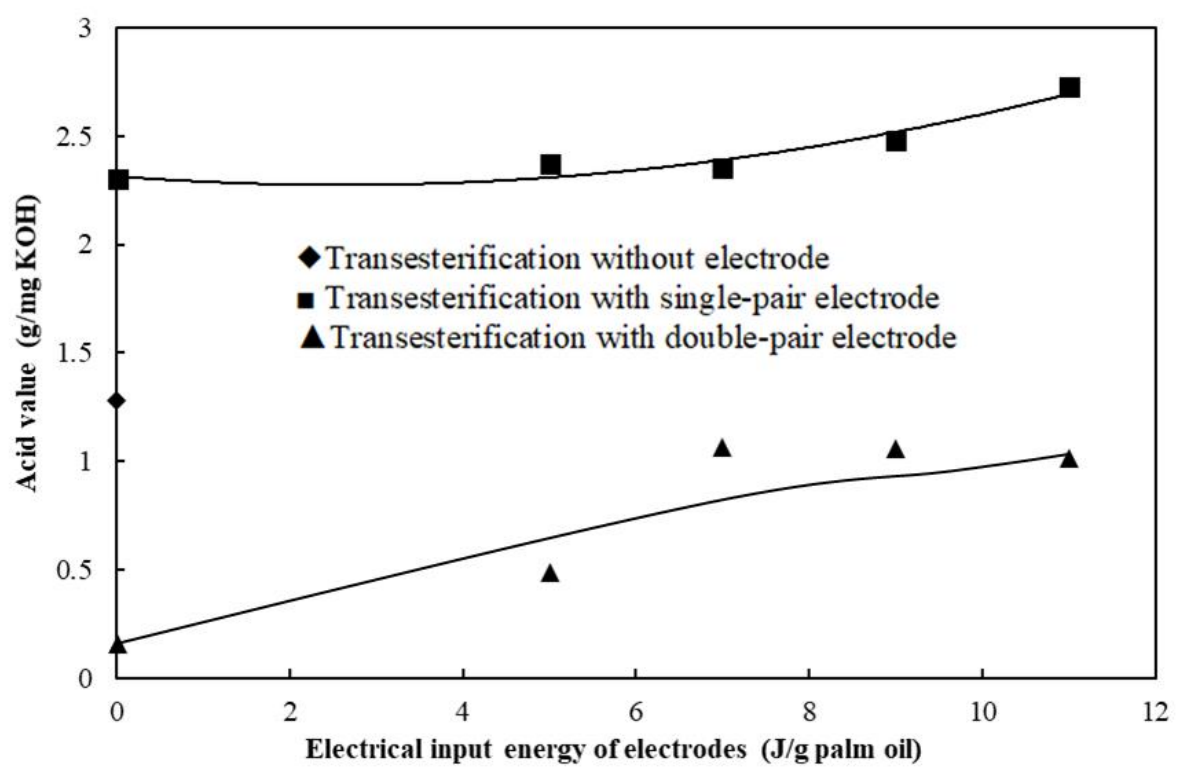

Figure 3. Effects of electrical energy input to electrodes for dissociating water on the acid value of biodiesel product.

Sakamura [23] and Siles et al. [24] found that when electrodes are immersed in a solution and provided with electrical energy, metallic ions are gradually released into the solution as the compounds in the solution are oxidized by the metallic electrodes. The metallic ions with positive charge attract free fatty acids with negative charge, resulting in saponification. The double-pair electrodes, which have a larger effective area $\left(3960 \mathrm{~mm}^{2}\right)$ than that of the single-pair electrodes $\left(1980 \mathrm{~mm}^{2}\right)$, released many more metallic ions which could react with free fatty acids, leading to a significantly lower acid value for the biodiesel sample produced using double-pair electrodes. The chemical radicals $\mathrm{H}^{+}$and $\mathrm{OH}^{-}$are prone to being released during the dissociation of water molecules in a reactant mixture under the application of an electric field by single- or double-pair electrodes. Hence, the conversion rate of feedstock oil was enhanced with the increase in input electrical energy, which agrees well with the finding of Guan and Kusakabe [25]. Much fewer, or even zero, $\mathrm{H}^{+}, \mathrm{OH}^{-}$, and $\mathrm{CH}_{3} \mathrm{O}^{-}$radicals might be formed under the effects of overpotential electrolysis on relatively low concentrations of water in the feedstock oil. The dissociating ability of triglyceride to form free fatty acids (FFA) was also promoted. In addition, methanol with a low boiling point was consumed during the electrolysis process. As a result, there was not enough methanol to react with the free fatty acid, leading to excess FFAs. Hence, the acid value of biodiesel increased with the rise of input electrical energy, as seen in Figure 3.

The water content properties of the biodiesels after application of the electrolytic reaction on the reactant mixture during transesterification are presented in Figure 4. The biodiesel electrolyzed by double-pair electrodes was observed to have the lowest water content, while the biodiesel without any electrolytic effect had the highest water content, reaching $0.346 \mathrm{wt} . \%$. The reason for this is that water in the reactant mixture was electrolyzed away during transesterification, resulting in a decrease in the water content of the biodiesel. The double-pair electrodes, which had a larger effective electrolytic area than that of the single-pair electrodes, removed much more water and thus achieved a lower water content than the latter. The increase in electrical energy input rendered a more intense electrolytic reaction for water removal. Therefore, Figure 4 shows the decreased water content resulting from an increase in input electrical energy. 


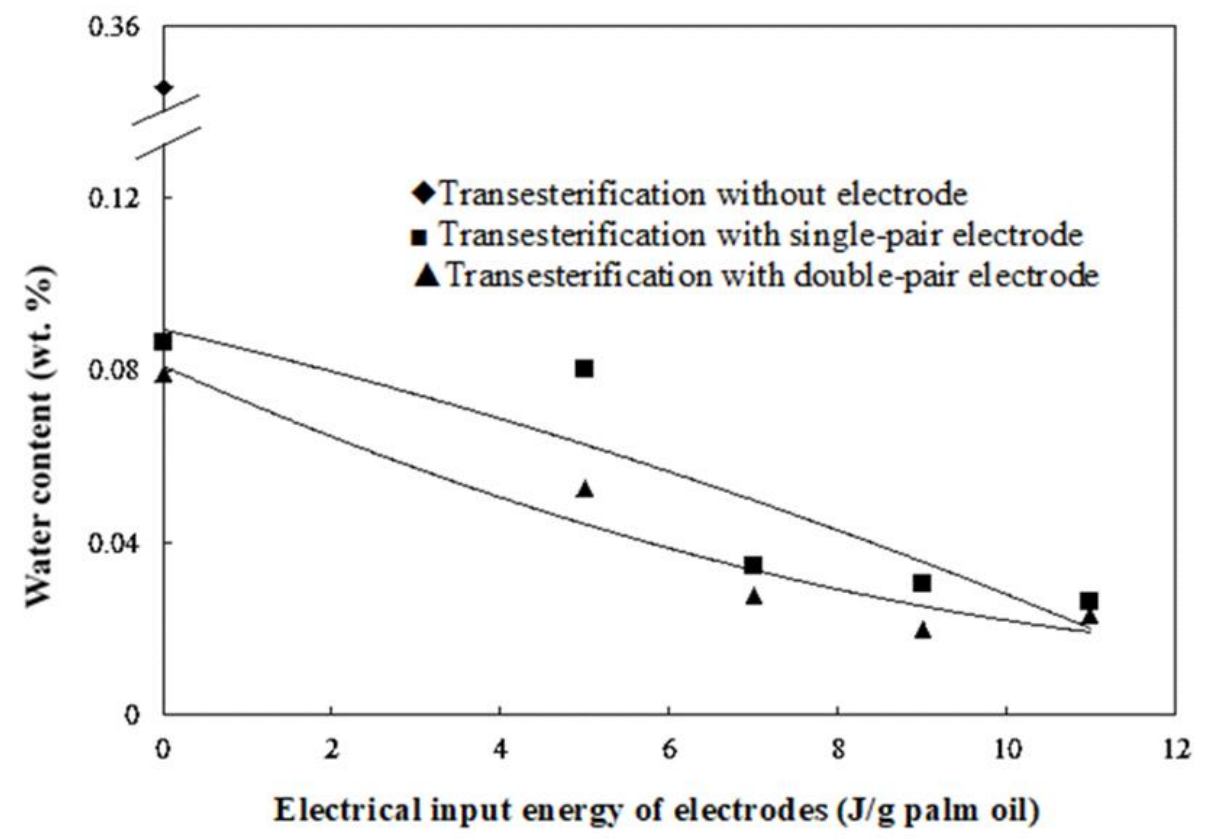

Figure 4. Effects of electrical energy input to electrodes for dissociating water on water content of biodiesel product.

The electric current density $(J)$ is defined as:

$$
J=I / A
$$

where $I$ is electric current and $A$ is electrode area. The electric current density decreased with increasing area of the electrodes under the same supplied electric current. When the water was removed by double-pair electrodes supplied with $9 \mathrm{~J} /(\mathrm{g}$ palm oil) electrical energy, the produced biodiesel appeared to have the lowest water content $(0.0304 \mathrm{wt} . \%$, see Figure 4) and the highest water-removal rate of $0.011 \mathrm{wt} . \% / \mathrm{min}$. The rate of water removal is defined as the amount of water removed from the reactant mixture per unit time.

\subsection{Heating Value}

The heating values of the biodiesel samples fell with an increase in input electrical energy, as seen in Figure 5. The biodiesel made from feedstock oil that was electrolyzed by the double-pair electrodes was shown to have a lower heating value than that produced using single-pair electrodes. In contrast, the biodiesel produced without any electrolytic effect attained the highest heating value of $41.8 \mathrm{MJ} / \mathrm{kg}$, probably owing to the lower acid value and thus the lower content of free fatty acids (FFA) in the biodiesel which was electrolyzed by single-pair electrodes for water removal. A small amount of water in feedstock oil would release hydrogen or hydroxyl ions during transesterification to facilitate the transesterification reaction and enhance the fuel characteristics. Hence, the biodiesel electrolyzed by the double-pair electrodes was observed to have the lowest water content and in turn the lowest heating value, as seen in Figures 4 and 5. The heating values of free fatty acids are generally lower than those of saturated fatty acid methyl esters due to the lower number of carbon atoms and covalent bonds in FFAs. The biodiesel treated with single-pair electrodes was observed to have higher heating values and acid values than that produced with double-pair electrodes, as seen in Figures 4 and 5. 


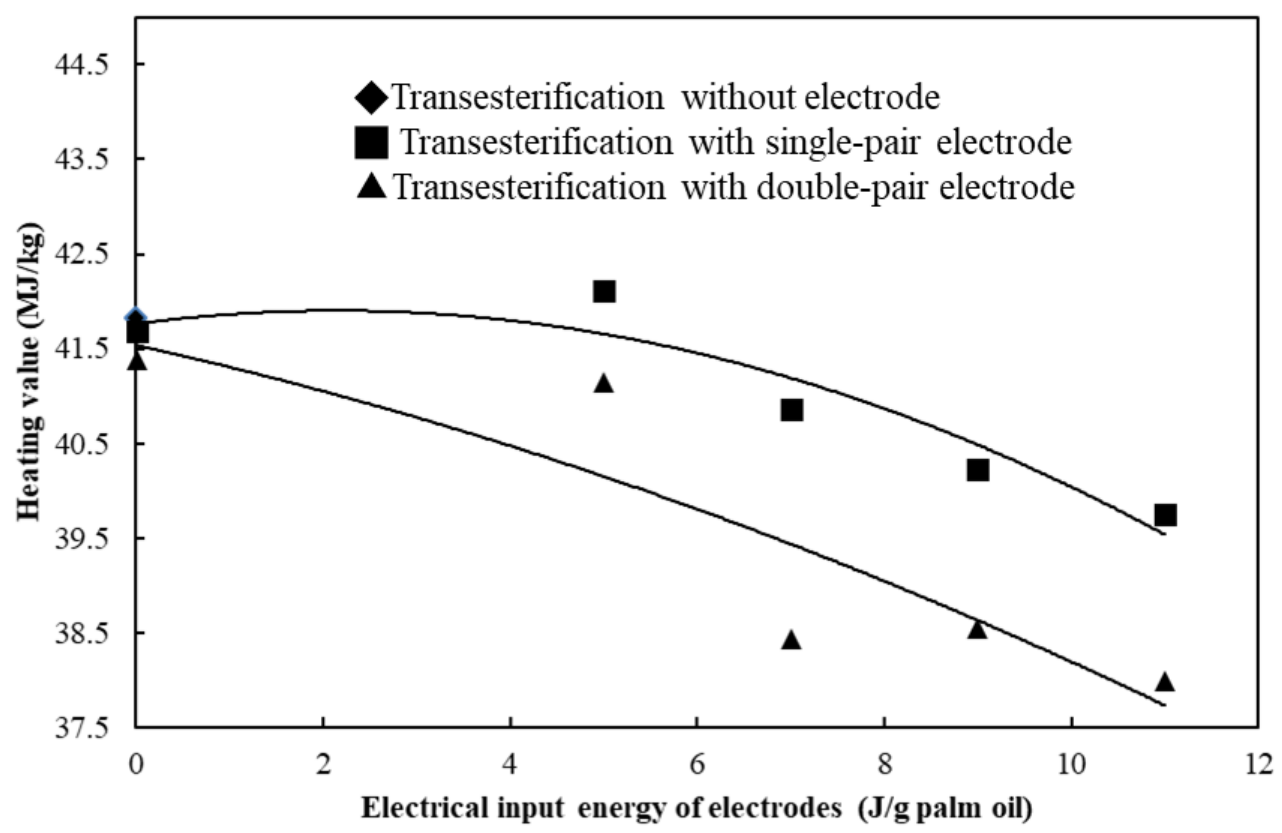

Figure 5. Effects of electrical energy input to electrodes for dissociating water on the heating value of biodiesel product.

When the single-pair electrodes were applied to electrolyze water in the feedstock oil during transesterification, there was a lower effective area accompanied by higher electric current density and thus higher ohmic impedance. Greater heat was thus generated due to ohmic impedance and accumulated at the reactive interface, resulting in the enhancement of the transesterification reaction rate and in turn a larger formation of fatty acid methyl esters [26]. Moreover, $\mathrm{OH}^{-}$concentration, which is formed from cathodic reduction, increased with a rise in electric current density. The higher electric current density of the single-pair electrodes facilitated the formation rate of $\mathrm{CH}_{3} \mathrm{O}^{-}$and water molecules from the methanol and $\mathrm{OH}^{-}$reaction during transesterification. The $\mathrm{CH}_{3} \mathrm{O}^{-}$radical is a significant radical in the transesterification reaction. As a consequence, the biodiesel made from palm oil with water electrolyzed away by single-pair electrodes appeared to have a higher heating value, as seen in Figure 5.

\subsection{Kinematic Viscosity}

The kinematic viscosity of the biodiesel made from palm oil electrolyzed by various pairs of electrodes is illustrated in Figure 6. More viscous biodiesel with larger input electrical energy was observed, probably due to the formation of more free fatty acids and greater saponification under larger electrical energy input, resulting in an increase in kinematic viscosity with increased input electrical energy, as seen in Figures 3 and 6. In addition, electrolysis by single-pair electrodes rendered larger kinematic viscosity of the biodiesel than in that produced by the double-pair electrodes when the input electrical energy was lower than $8 \mathrm{~J} /$ (g palm oil). The kinematic viscosity of the biodiesel increased with the increase in input electrical energy, and reached $5.15 \mathrm{~mm}^{2} / \mathrm{s}$ when water in the feedstock oil was electrolyzed by double-pair electrodes with input electrical energy of $11 \mathrm{~J} /$ (g palm oil). 


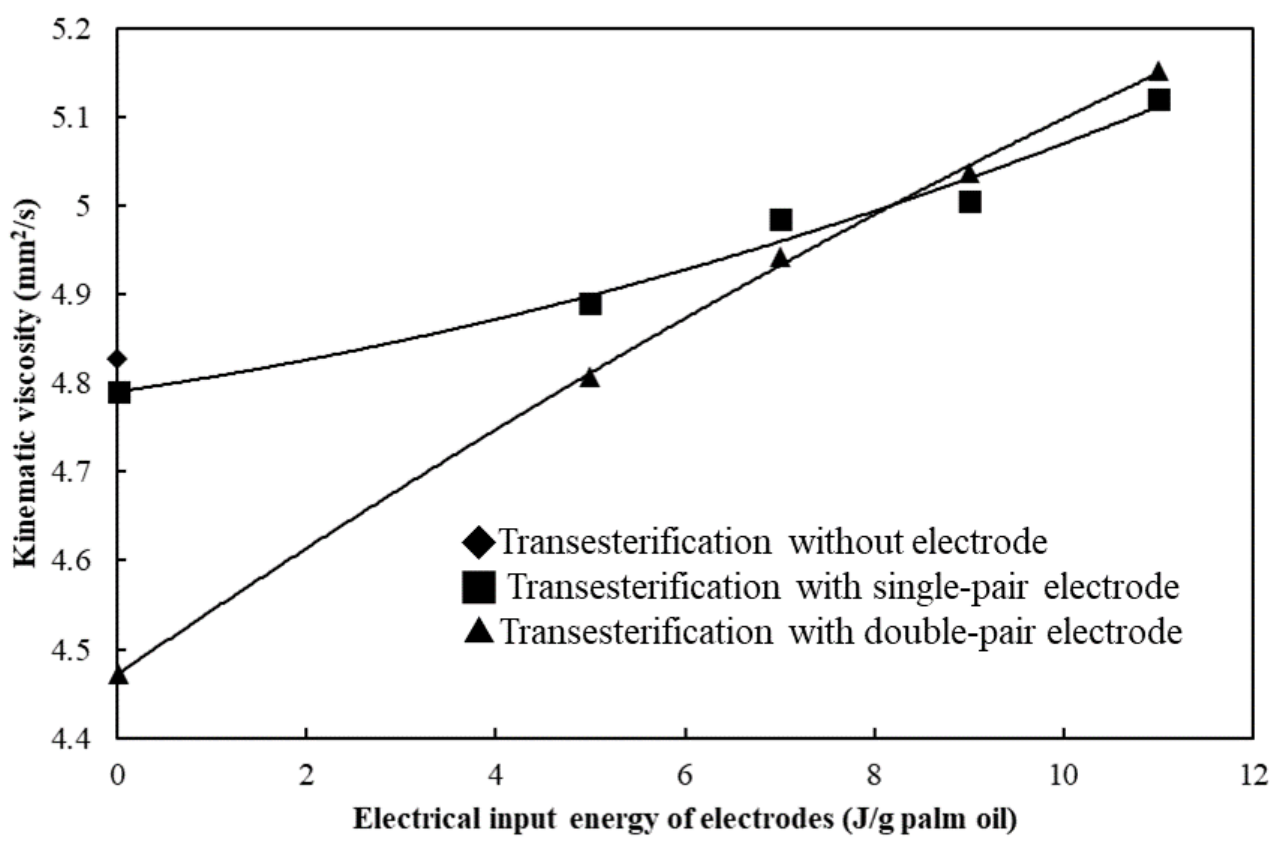

Figure 6. Effects of electrical energy input to electrodes for dissociating water on the kinematic viscosity of biodiesel product.

Electrolysis by the double-pair electrodes resulted in lower water content in the biodiesel than in that produced by the single-pair electrodes, as shown in Figure 4. Hence, a lower interfacial area of the single-pair electrodes was surrounded by the reactant mixture of water and palm oil during transesterification, resulting in less heat absorbed by the reactant and thus larger kinematic viscosity of the biodiesel, as seen in Figure 6. In addition, the double-pair electrodes had a larger effective area of reaction to release more $\mathrm{Cr}$, $\mathrm{Fe}$, and $\mathrm{Ni}$ ions from the SUS 304 stainless steel electrode, leading to greater production of free fatty acids and increased saponification. When the input electrical energy was $0.01 \mathrm{~J} /(\mathrm{g}$ palm oil), the kinematic viscosity appeared to be the lowest, accompanied by the lowest content of free fatty acids and acid value, as presented in Figure 3. Shah et al. [27] also confirmed the positive relationship between kinematic viscosity and free fatty acids in liquid biofuel.

\subsection{Specific Gravity}

Dunn et al. [28] found that the specific gravity of biodiesel is positively related to the heating value. The specific gravity was found to decrease with greater input electrical energy for those biodiesels electrolyzed by two various pairs of electrodes, as seen in Figure 7. The biodiesel in which water in feedstock oil was electrolyzed away by doublepair electrodes appeared to have lower specific gravity than in those produced by single-pair electrodes or without any electrolyzing effect. The biodiesel without any electrolysis effect to remove water had the highest specific gravity $(0.876)$. The curve trends for specific gravity in Figure 7 are similar to those for the heating value in Figure 5. This is ascribed to the increase of transesterification with a rise in input electrical energy. Hence, a larger glycerol content with higher density was formed from triglyceride in feedstock oil during transesterification. After separation from heavier glycerol by virtue of gravity difference, the biodiesel product was found to have decreased specific gravity with increased input electrical energy. 


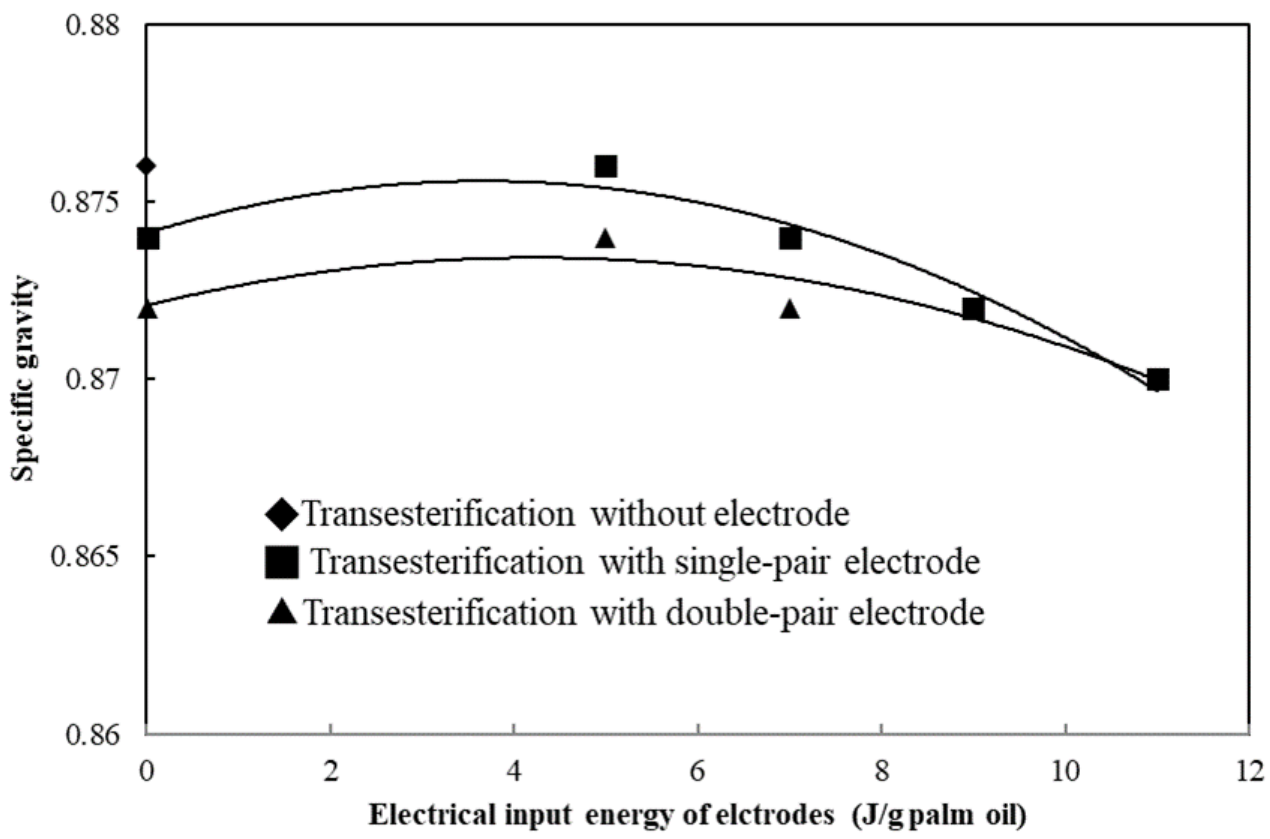

Figure 7. Effects of electrical energy input to electrodes for dissociating water on the specific gravity of biodiesel product.

When the single-pair electrodes were used to electrolyze water from feedstock oil, the effective area of the electrodes was smaller, thus resulting in higher electric current density. Higher ohmic impedance was therefore produced, which generated greater heat at the reactive interface of the single-pair electrodes. More $\mathrm{CH}_{3} \mathrm{O}^{-}$radicals were formed to facilitate greater transesterification of triglyceride with methanol. Higher specific gravity accompanied by a higher heating value for the biodiesel electrolyzed by single-pair electrodes that that produced by double-pair electrodes was thus produced, as seen by comparing Figures 3 and 5 .

As shown in Table 1, the biodiesel electrolyzed by single-pair electrodes appeared to have a slightly higher content $(0.74 \mathrm{wt} . \%)$ of longer carbon-chained fatty acids ranging from C20 to C24 than that produced by double-pair electrodes, probably because of the higher electric current density of the former's electrodes. Ivanova et al. [29] found that a higher content of long carbon-chained fatty acids caused greater lipid density. The feedstock oil rendered by greater input electrical energy or the larger electric current density of singlepair electrodes during transesterification was apt to produce more long carbon-chained fatty acids, resulting in higher specific gravity than in that produced by double-pair electrodes, as seen in Figure 7. In addition, the larger content of unsaturated fatty acids formed due to the effect of the single-pair electrodes with higher electric current density than that produced by double-pair electrodes can also be observed in Table 1.

Table 1. Fatty acid compositions of biodiesel after being water-electrolyzed by single- and double-pair electrodes with an input electrical energy of $9 \mathrm{~J} /(\mathrm{g}$ palm oil).

\begin{tabular}{ccc}
\hline \multirow{2}{*}{ Compositions } & \multicolumn{2}{c}{ Number of Electrodes } \\
\cline { 2 - 3 } & \multicolumn{3}{c}{ Single Pair } & Double Pair \\
\cline { 2 - 3 } & \multicolumn{3}{c}{ Results (wt. \%) } \\
\hline Myristic acid (14:0) & 36.58 & 37.96 \\
Palmitic acid (16:0) & 0.22 & 0.38 \\
Palmitoleic acid (16:1) & 3.90 & 3.93 \\
Stearic acid (18:0) & & \\
\hline
\end{tabular}


Table 1. Cont.

\begin{tabular}{ccc}
\hline \multirow{2}{*}{ Compositions } & \multicolumn{2}{c}{ Number of Electrodes } \\
\cline { 2 - 3 } & Single Pair & Double Pair \\
\cline { 2 - 3 } & \multicolumn{2}{c}{ Results (wt. \%) } \\
\hline Oleic acid (18:1) & 45.35 & 45.06 \\
Linoleic acid (18:2n -6) & 12.09 & 11.78 \\
Linolenic acid (18:3n - 3) & 0.10 & 0.10 \\
Arachidic acid (20:0) & 0.36 & 0.33 \\
Eicosenoic acid (20:1) & 0.19 & 0.18 \\
Behenic acid (22:0) & 0.06 & 0.04 \\
Erucic acid (22:1) & 0.02 & 0.01 \\
Lignoceric acid (24:0) & 0.07 & 0.05 \\
Docosahexaenoic acid (22:6n -3$)$ & 0.04 & 0.05 \\
Longer carbon-chained fatty acids & 0.74 & 0.66 \\
(C20-C24) & 42.00 & 42.43 \\
Total saturated fatty acids & 45.78 & 45.63 \\
Mono-unsaturated fatty acids & 12.23 & 11.93 \\
Poly-unsaturated fatty acids & & \\
\hline
\end{tabular}

\subsection{Flash Point and Ignition Point}

The flash point and ignition point of the biodiesel electrolyzed by single- and doublepair electrodes or without electrolysis are compared in Figures 8 and 9, respectively. The flash point fell with an increase in either the input electrical energy or the number of electrodes. In comparison with the acid value results presented in Figure 1, this is probably due to the high free fatty acid content or the equivalently high acid value under increased input electrical energy. The curve trend for the specific gravity of the biodiesel in Figure 5 is similar to that of the flash point in Figure 8 and the ignition point in Figure 9, which agrees well with Kumar and Bansal [30].

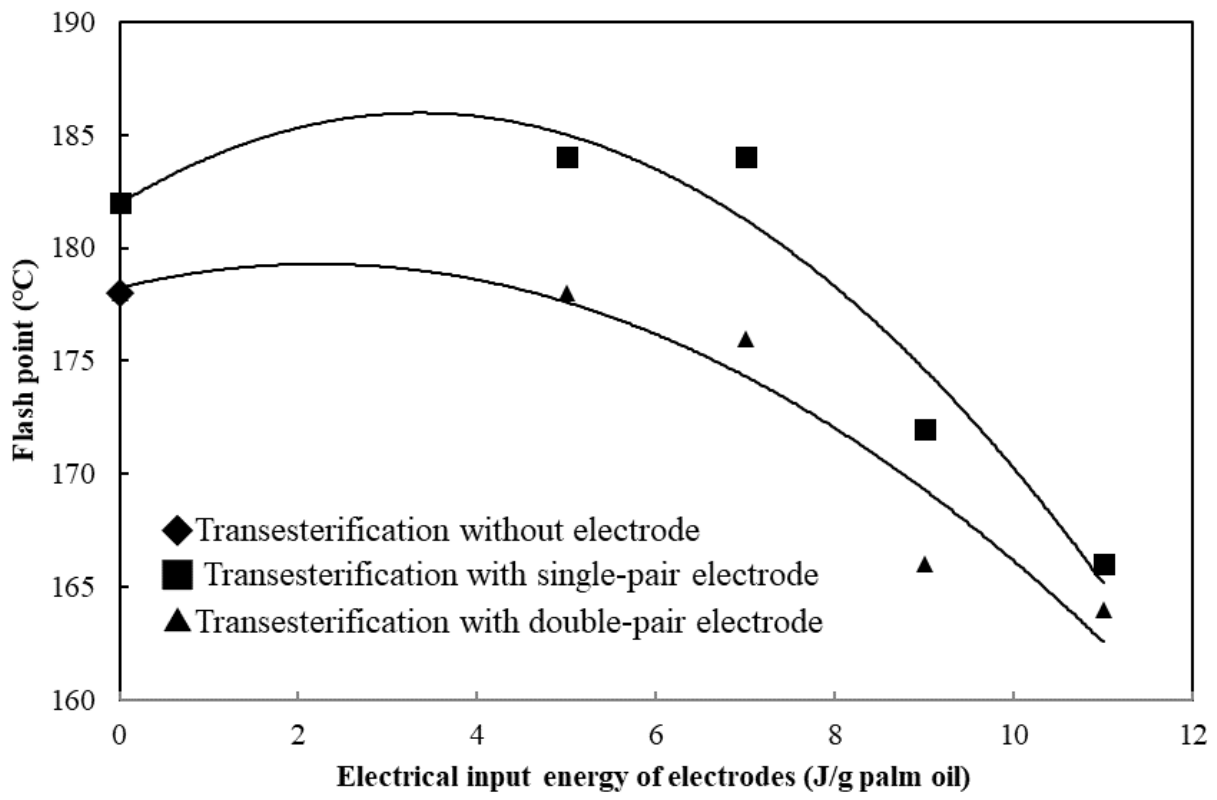

Figure 8. Effects of electrical energy input to electrodes for dissociating water on the flash point of biodiesel product. 


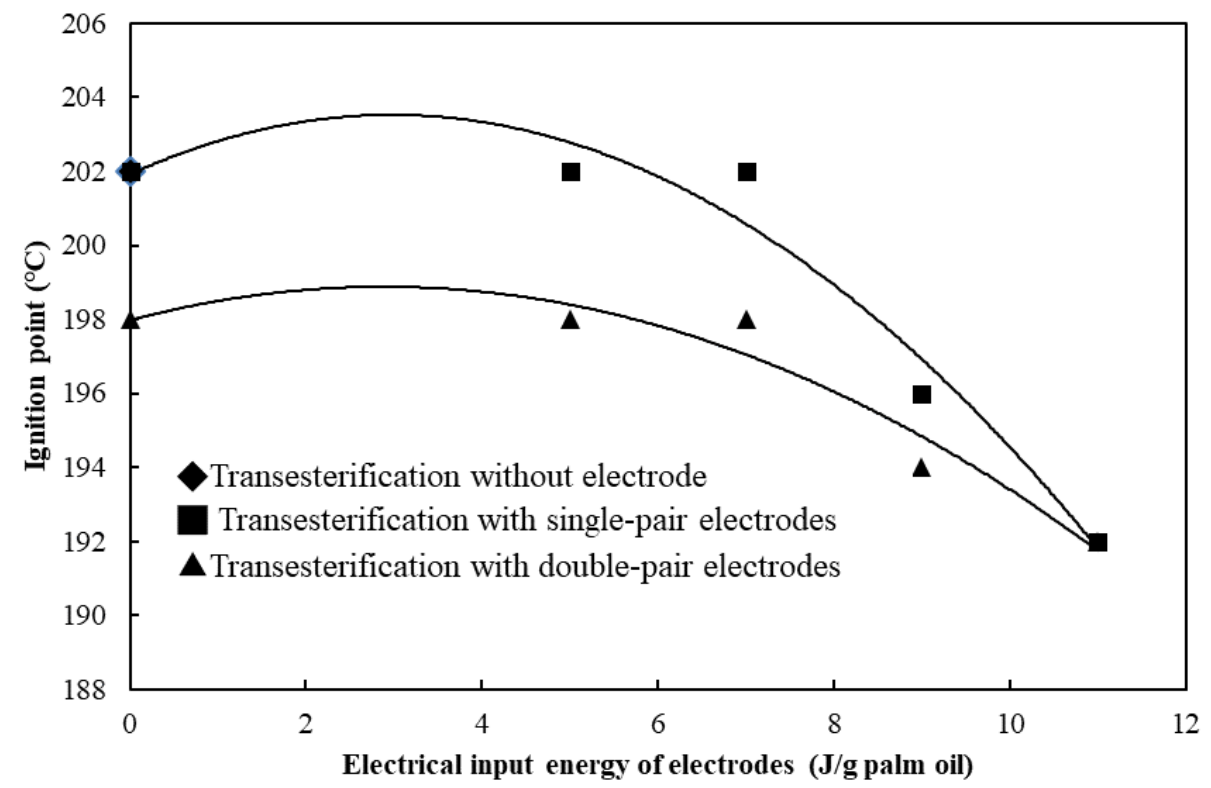

Figure 9. Effects of electrical energy input to electrodes for dissociating water on the ignition point of biodiesel product.

The electrolysis effect during transesterification enhances both nucleophilic substitution reactions between methanol and triglycerides and the conversion rate from feedstock oil [31]. The flash point of the biodiesel electrolyzed for water removal by single-pair electrodes was found to be higher than that produced by double-pair electrodes. This is ascribed to the larger effective reactive area between the double-pair electrodes and the reactant mixture of feedstock oil. The electric current density of the double-pair electrodes is only one half that of the single-pair electrodes. This led to much less formation of $\mathrm{CH}_{3} \mathrm{O}^{-}$ radicals from the cathodes of the double-pair electrodes than from that of the single-pair electrodes, resulting in a lower conversion rate of transesterification under the effect of the double-pair electrodes. Moreover, the significantly greater amount of heat generated due to ohmic impedance between the feedstock oil and the single-pair electrodes might facilitate the yield of fatty acid methyl esters (FAME). A higher flash point and ignition point for the biodiesel electrolyzed by the single-pair electrodes was thus seen. The increase in input electrical energy to the electrodes resulted in a decreased conversion rate of transesterification and thus lower flash and ignition points.

As seen from Table 1, a larger amount of longer carbon-chained fatty acids in the range between C20 and to C24 was produced after application of the single-pair electrodes to remove water from the reactant mixture during the transesterification reaction. Hence, a higher flash point and ignition point appeared for the biodiesel electrolyzed by the single-pair electrodes, as seen in Figures 8 and 9.

\subsection{Distillation Temperature}

Figure 10 shows the distribution curve of distillation temperatures, which is also termed the ASTM D86 distillation temperature curve of the biodiesels electrolyzed by single- or double-pair electrodes. The effects of different electrical energy inputs, including 0,5 , and $11 \mathrm{~J} /$ (g palm oil), on the distillation temperature were observed. The distillation temperatures of the biodiesel electrolyzed by the single-pair electrodes are shown in Figure 10a. The highest distillation temperature $\left(362{ }^{\circ} \mathrm{C}\right)$ appeared after the reactant mixture for the transesterification reaction was electrolyzed with $11 \mathrm{~J} /(\mathrm{g}$ palm oil) electrical energy input through the single-pair electrodes. In comparison with the results for specific gravity in Figure 7, the lowest specific gravity was observed for the biodiesel electrolyzed with input electrical energy of $11 \mathrm{~J} /(\mathrm{g}$ palm oil). This is probably because the efficiency of the transesterification reaction increased under the effect of the higher electrical energy 
input of $11 \mathrm{~J} /$ (g palm oil), such that greater contents of lighter compounds were produced, resulting in a lower specific gravity for this biodiesel product. In contrast, the biodiesel electrolyzed by single-pair electrodes with lower input energy of $5 \mathrm{~J} /$ (g palm oil) was shown to have higher specific gravity, as seen in Figure 7, and thus formed heavier compounds with lower distillation temperatures, as seen in Figure 10a.

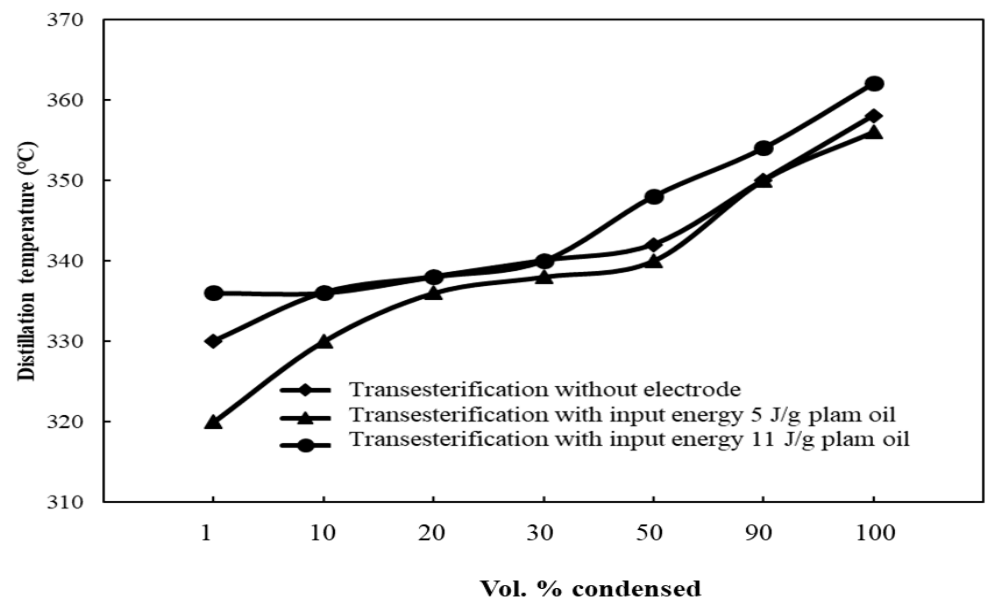

(a) Single-pair electrodes

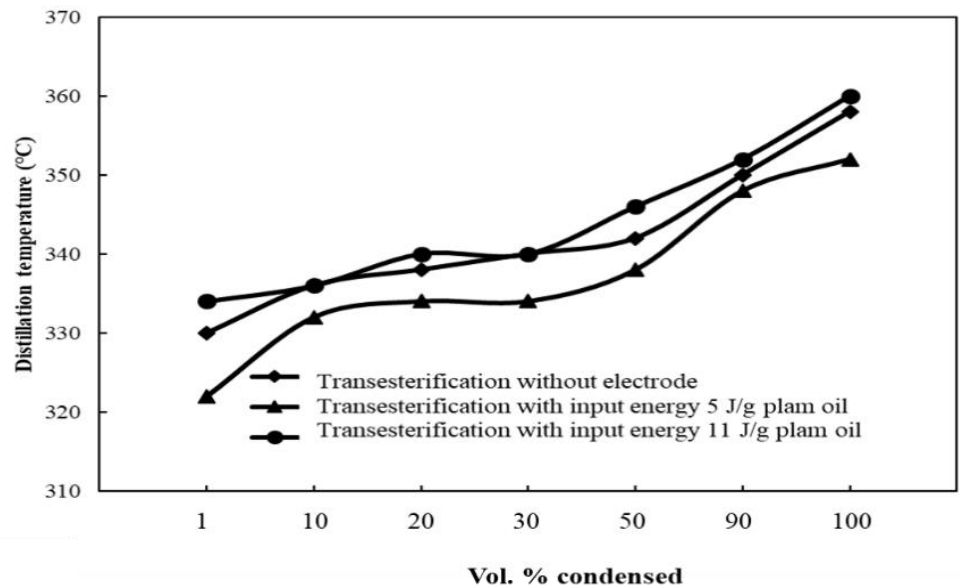

(b) Double-pair electrodes

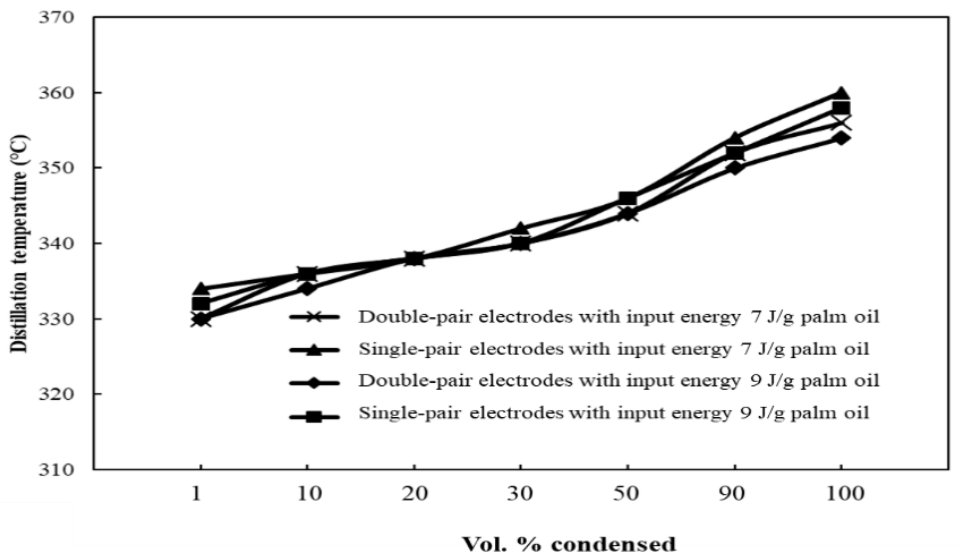

(c) Various pairs of electrodes

Figure 10. Effects of electrical energy input and number of electrodes for (a) single-pair, (b) doublepair, and (c) various pairs of electrodes for dissociating water on the distillation temperature of biodiesel product. 
Windom and Bruno [32] found that the distillation temperature of biodiesel increased with higher contents of long carbon-chained fatty acids and poly-unsaturated fatty acids. Larger input electrical energy to the electrodes to electrolyze away the water in the raw oil mixture during the transesterification reaction might facilitate the formation of polyunsaturated fatty acids and therefore deteriorate the stability of the biodiesel product. The distillation temperature distribution of the biodiesel after being electrolyzed by the double-pair electrodes under various inputs of electrical energy is shown in Figure 10b. The curve trend in Figure 10b is similar to that of the distillation temperature in Figure 10a. The biodiesel product electrolyzed for water removal with input electrical energy of $11 \mathrm{~J} /$ (g palm oil) during transesterification was observed to have the highest distillation temperature $\left(360^{\circ} \mathrm{C}\right)$ among the three cases of input electrical energy in Figure $10 \mathrm{~b}$.

The distillation temperatures of the biodiesels facilitated by single- and double-pair electrodes with 7 and $9 \mathrm{~J} /$ (g palm oil) are compared in Figure 10c. The biodiesel electrolyzed by single-pair electrodes had a higher distillation temperature than that produced by the double-pair electrodes under the same input electrical energy. This is ascribed to the larger reactive area and lower electric current density of the double-pair electrodes, leading to the formation of significantly fewer $\mathrm{OH}^{-}$and in turn $\mathrm{CH}_{3} \mathrm{O}^{-}$radicals. A lower conversion rate of biodiesel from feedstock palm oil was thus produced due to the above effects of double-pair electrodes. This was followed by the formation of larger contents of saturated fatty acids and shorter carbon-chained fatty acids by the double-pair electrodes, as shown in Table 1.

Comparing Figure 7 with Figure 10c, the biodiesel influenced by the double-pair electrodes appears to have a larger content of lighter compounds, lower specific gravity, and lower distillation temperature. The $\mathrm{T}_{50}$ distillation temperatures corresponding to 50 vol.\% liquid fuel distilled, condensed, and collected under various input electrical energies and numbers of electrodes are shown in Figure 11. The $\mathrm{T}_{50}$ data seem to increase with greater electrical energy input and decrease with a higher number of electrodes. Greater electrical energy input or electric current density enhanced the formation of $\mathrm{CH}_{3} \mathrm{O}^{-}$ radicals and the transesterification reaction [33] in turn. More longer carbon-chained fatty acids ranging from C20 to C24 were produced accordingly. The biodiesel electrolyzed by the single-pair electrodes was subjected to greater electric current density to achieve higher $\mathrm{T}_{50}$ than that in that produced by double-pair electrodes, as seen in Figure 11. In contrast, the biodiesel electrolyzed with input electrical energy of $5 \mathrm{~J} /$ (g palm oil) was observed to have the lowest $\mathrm{T}_{50}$ (i.e., $348^{\circ} \mathrm{C}$ ) among the biodiesels in Figure 11.

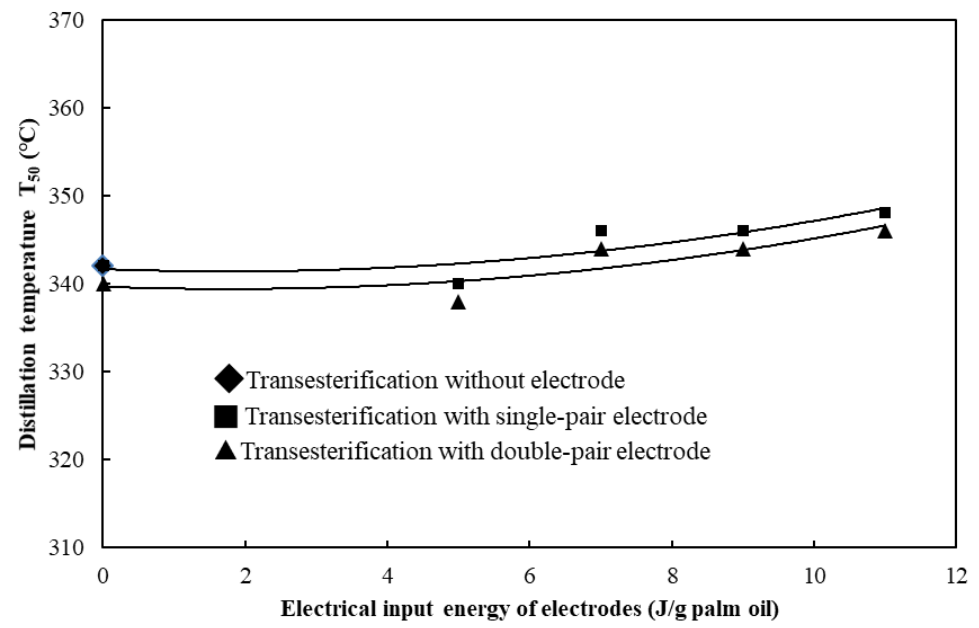

Figure 11. Effects of electrical energy input for dissociating water on $50 \mathrm{vol} . \%$ distillation temperature of biodiesel product. 


\subsection{Cetane Index}

Cetane index (CI), which is calculated based on Equation (1) using $\mathrm{T}_{50}$ and specific gravity (sg) data, represents the compression-ignition quality of distilled fuel in an internal combustion engine. Higher CI implies shorter ignition delay and hence superior combustion characteristics. The cetane indices of the biodiesels electrolyzed by various numbers of electrodes for water removal during the transesterification reaction are compared in Figure 12. The lowest cetane index appeared when the reactant feedstock oil was electrolyzed by single-pair electrodes supplied with electrical energy of $5 \mathrm{~J} /$ (g palm oil). An increase in the input of electrical energy enhanced the transesterification reaction and increased the cetane index to reach the highest CI (i.e., 50.05) at $11 \mathrm{~J} /$ (g palm oil). Less water and lighter compounds were formed, which led to a decrease in the specific gravity of the biodiesel product. In comparison with Figures 5 and 10, an increase in specific gravity decreased the cetane index. Hence, higher electrical energy input for electrolysis of the feedstock oil led to a higher CI of the biodiesel, as seen in Figure 12.

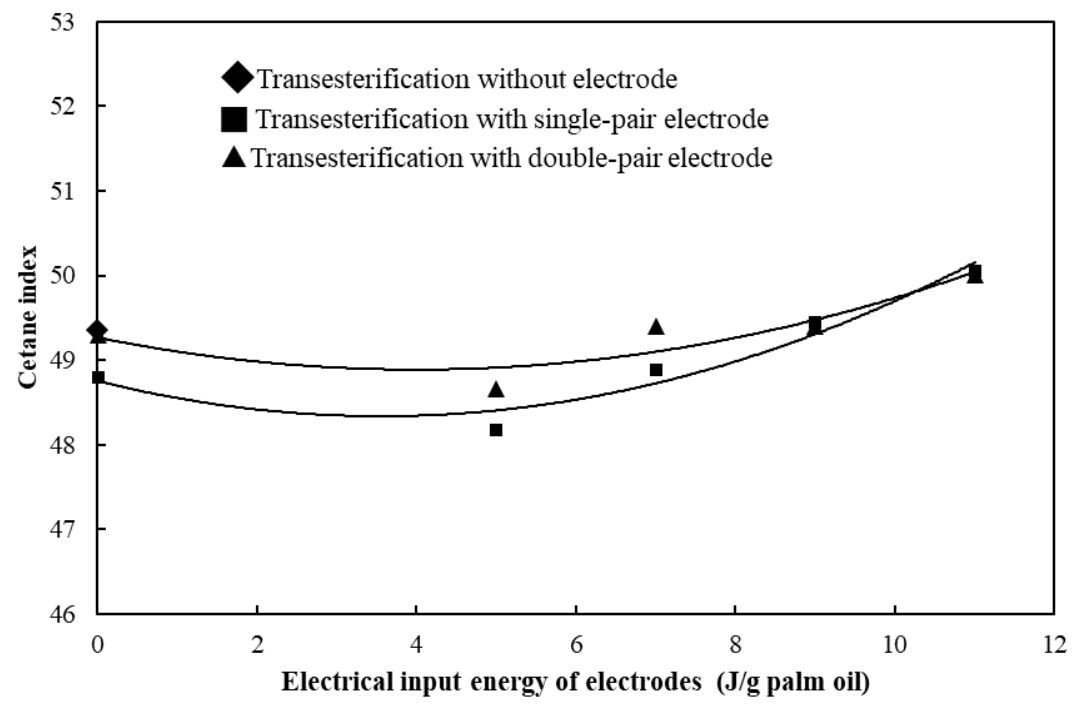

Figure 12. Effects of electrical energy input for dissociating water on the cetane index of biodiesel product.

Lower $\mathrm{T}_{50}$ of the biodiesel product tended to cause a larger cetane index, as seen by comparing Figures 11 and 12. Greater formation of long carbon-chained fatty acids under the effect of higher electrical energy input caused a higher cetane number [34] in the biodiesel. The biodiesel electrolyzed by single-pair electrodes was found to have a lower cetane index than the biodiesels produced using double-pair electrodes or without the electrolysis effect.

\subsection{Comparison of Water Removal Rate between Different Water-Removal Methods}

Two different water-removal methods were used: molecular sieves with vibrating rotation and electrodes for electrolysis. The water-removal efficiencies of those two methods are compared in Table 2. The water-removal rate of the vibrating molecular sieve was the highest at 11.24 times the lowest rate, achieved by single-pair electrodes with input electrical energy of $0.01 \mathrm{~J} /$ (g palm oil). This is due to the more effective water-removal efficiency of molecular sieves accompanied with vibrating rotation motion in comparison with that achieved by electrolyzing water away using electrodes. However, when the dewatering function of the used molecular sieves must be regenerated, they are heated at $300{ }^{\circ} \mathrm{C}$ for $5 \mathrm{~h}$ in a high-temperature furnace. This causes the water-removal process by molecular sieves to consume more energy than those using electrodes. 
Table 2. Comparison of water removal rates between rotary-vibrating molecular sieves and electrolysis via electrodes.

\begin{tabular}{ccc}
\hline Methods & \multicolumn{2}{c}{ Rate of Water Removal (wt.\%/min) } \\
\hline Vibrating Molecular Sieves & \multicolumn{2}{c}{$\mathbf{0 . 0 9 6 7}$} \\
\hline \multirow{2}{*}{ Input Electrical Energy (J/(g Palm Oil)) } & \multicolumn{2}{c}{ Number of Electrodes } \\
\cline { 2 - 3 } & Single Pair & Double Pair \\
\hline 0.01 & 0.0086 & 0.0089 \\
5 & 0.0089 & 0.0098 \\
7 & 0.0104 & 0.0106 \\
9 & 0.0105 & 0.0109 \\
11 & 0.0107 & 0.0108 \\
\hline
\end{tabular}

\section{Conclusions}

This study used two methods to remove water from the reactant mixture of palm oil, methanol, and the strong alkaline catalyst $\mathrm{NaOH}$ during the transesterification reaction step of biodiesel production: molecular sieves with rotary-vibrating motion and single- and double-pair electrodes. The water-removal rates of those two water-removal methods and the fuel properties of the palm-oil biodiesels after water removal during transesterification were analyzed and compared. The experimental results are summarized as follows.

After water was removed via the electrolysis effect of electrodes during a transesterification reaction, the biodiesel product demonstrated increased acid value, kinematic viscosity, distillation temperature, and cetane index with an increase in electrical energy input. In contrast, the properties of water content, heating value, specific gravity, flash point, and ignition point decreased with a higher input of electrical energy to the electrodes. In addition, the biodiesel electrolyzed by double-pair electrodes was observed to have lower acid value and water content than that produced by single-pair electrodes under the same input electrical energy. Electrolysis by double-pair electrodes was more effective at reducing the water content and acid value of the biodiesel product. The lowest water content $(0.0304 \mathrm{wt} . \%)$ together with the highest water-removal rate $(0.011 \mathrm{wt} . \%)$ were found for the biodiesel which was water-electrolyzed by double-pair electrodes with electrical energy of $9 \mathrm{~J} /$ (g palm oil) during transesterification. The highest kinematic viscosity $\left(5.15 \mathrm{~mm}^{2} / \mathrm{s}\right)$ of the biodiesel was found when electrolysis with double-pair electrodes and input electrical energy of $11 \mathrm{~J} /$ (g palm oil) was applied. The water-removal rate of the rotary-vibrating molecular sieves with high water absorbance capability was about 11.24 times that of the lowest water-removal rate of the single-pair electrodes with electrical energy input of $0.01 \mathrm{~J} /$ (g palm oil). Longer carbon-chained fatty acids ranging from C20 to C24 amounted to $0.74 \mathrm{wt} . \%$ of the biodiesel produced using double-pair electrodes because their electrolytic effect was greater than that of the single-pair electrodes. Moreover, the used molecular sieves need to be heated at $300{ }^{\circ} \mathrm{C}$ for $5 \mathrm{~h}$ in a high-temperature furnace to regenerate their dewatering function. Hence, water removal by molecular sieves consumed more energy than electrolysis using electrodes for the same amount of water removed. Therefore, double-pair electrodes were more effective at removing water from the reactant mixture during transesterification, resulting in superior fuel properties in this biodiesel product than in the biodiesel produced using single-pair electrodes.

Author Contributions: Conceptualization, C.-Y.L.; methodology, C.-Y.L.; validation, L.M.; formal analysis, C.-Y.L.; investigation, L.M.; resources, C.-Y.L.; data curation, L.M.; writing-original draft preparation, L.M. and C.-Y.L.; writing-review and editing, C.-Y.L.; supervision, C.-Y.L.; project administration, C.-Y.L.; funding acquisition, C.-Y.L. All authors have read and agreed to the published version of the manuscript.

Funding: This research was funded by the Ministry of Science and Technology, Taiwan under grant number MOST 107-2221-E-019-056-MY2. The APC was funded by the National Taiwan Ocean University, Taiwan. 
Institutional Review Board Statement: Not applicable.

Informed Consent Statement: Not applicable.

Data Availability Statement: The data presented in this study are contained within this article.

Conflicts of Interest: The authors declare no conflict of interest.

\section{Nomenclature}

$\begin{array}{ll}\text { Abbreviation } & \text { Full Name } \\ \text { A } & \text { Electrode area } \\ \text { AC } & \text { Alternating current } \\ \text { API } & \text { American Petroleum Institute } \\ \text { ASTM } & \text { American Society of Testing and Materials } \\ \text { CI } & \text { Cetane index } \\ \text { cSt } & \text { Centistoke } \\ \text { DC } & \text { Direct current } \\ \text { EN } & \text { European Norms } \\ \text { FAEE } & \text { Fatty acid ethyl esters } \\ \text { FAME } & \text { Fatty acid methyl esters } \\ \text { FFA } & \text { Free fatty acids } \\ \text { I } & \text { Electric current } \\ \mathrm{J} & \text { Electric current density } \\ \mathrm{KOH} & \text { Potassium hydroxide } \\ \mathrm{NaOH} & \text { Sodium hydroxide } \\ \mathrm{SG} & \text { Specific gravity } \\ \mathrm{SUS} & \text { Steel use stainless } \\ \mathrm{T}_{50} & \text { Temperature at which } 50 \text { vol.\% liquid fuel was distilled and collected } \\ \mathrm{T}_{\mathrm{IBP}} & \text { Temperature at which first liquid drop was distilled and collected }\end{array}$

\section{References}

1. Alami, A.H.; Alasad, S.; Ali, M.; Alshamsi, M. Investigating algae for $\mathrm{CO}_{2}$ capture and accumulation and simultaneous production of biomass for biodiesel production. Sci. Total Environ. 2021, 759, 143529. [CrossRef]

2. Lin, C.Y. Effects of biodiesel blend on marine fuel characteristics for marine vessels. Energies 2013, 6, 4945-4955. [CrossRef]

3. Chanakaewsomboon, I.; Tongurai, C.; Photaworn, S.; Kungsanant, S.; Nikhom, R. Investigation of saponification mechanisms in biodiesel production: Microscopic visualization of the effects of FFA, water and the amount of alkaline catalyst. J. Environ. Chem. Eng. 2020, 8, 103538. [CrossRef]

4. di Bitonto, L.; Pastore, C. Metal hydrated-salts as efficient and reusable catalysts for pre-treating waste cooking oils and animal fats for an effective production of biodiesel. Renew. Energy 2019, 143, 1193-1200. [CrossRef]

5. Ma, F.; Hanna, M.A. Biodiesel production: A review. Bioresour. Technol. 1999, 70, 1-15. [CrossRef]

6. Canakci, M.; Gerpen, J.V. Biodiesel production via acid catalysis. Trans. ASAE 1999, 42, 1203-1210. [CrossRef]

7. Tang, Y. Transesterification of rapeseed oil to biodiesel by using $\mathrm{CaO}$ as a heterogeneous catalys. J. Anhui Agric. Sci. 2009, 37, 10858-10859.

8. Son, J.; Kim, B.; Park, J.; Yang, J.; Lee, J.W. Wet in situ transesterification of spent coffee grounds with supercritical methanol for the production of biodiesel. Bioresour. Technol. 2018, 259, 465-468. [CrossRef] [PubMed]

9. Hakimi, M.I.; Goembira, F.; Ilham, Z. Engine-compatible biodiesel from Leucaena leucocephala seed oil. J. Soc. Automot. Eng. Malays. 2017, 1, 86-93.

10. Lin, C.Y.; Ma, L. Influences of water content in feedstock oil on burning characteristics of fatty acid methyl esters. Processes $\mathbf{2 0 2 0}$ 8, 1130. [CrossRef]

11. Lee, J.; Ho, T.L.; Kim, H.Y.; Park, J.H.; Kim, B.K. Direct electrolysis and detection of single nanosized water emulsion droplets in organic solvent using stochastic collisions. Electroanalysis 2019, 31, 167-171. [CrossRef]

12. Yuksel, A.; Sasaki, M.; Goto, M. Electrolysis reaction pathway for lactic acid in subcritical water. Ind. Eng. Chem. Res. 2011, 50, 728-734. [CrossRef]

13. Pozlo, A.; Francesco, M.D.; Jovanovic, Z.; Tosti, S. Pd-Ag hydrogen diffusion cathode for alkaline water electrolysers. Int. J. Hydrogen Energy 2011, 36, 5211-5217.

14. Millet, P.; Andolfatto, F.; Durand, R. Design and performance of a solid polymer electrolyte water electrolyzer. Int. J. Hydrogen Energy 1996, 21, 87-93. [CrossRef] 
15. Camacho, L.F.D.; Puentes, Z.; Calderón, J.; Lucena, E.; Moncada, J.; Saavedra, K. Assisted electrochemical hydroconversion of heterocompounds present in fuel and oil using active hydrogen passing through a Pd membrane. Pet. Sci. Technol. 2011, 29, 529-534. [CrossRef]

16. Hu, Z.Y.; Li, Y.L.; Shen, P.K. Hydrogen production by methanol electrolysis. Battery Bimon. 2006, 36, 383-384.

17. Lin, C.Y.; Ma, L. Fluid characteristics of biodiesel produced from palm oil with various initial water contents. Processes 2021, 9 , 309. [CrossRef]

18. Xu, X.; Xu, Y.; Ma, J.; Yin, Y.; Fronzi, M.; Wang, X.; Bi, L. Tailoring electronic structure of perovskite cathode for proton-conducting solid oxide fuel cells with high performance. J. Power Sources 2021, 489, 229486. [CrossRef]

19. Ghatee, M.H.; Koleini, M.M. Bonding, structural and thermodynamic analysis of dissociative adsorption of $\mathrm{H}_{3} \mathrm{O}^{+}$ion onto calcite $\left(101^{-} 4\right)$ surface: CPMD and DFT calculations. J. Mol. Modeling 2017, 23, 331. [CrossRef] [PubMed]

20. Awad, O.I.; Mamat, R.; Ibrahim, T.K.; Kettner, M.; Kadirgama, K.; Leman, A.M.; Saiful, A.I.M. Effects of fusel oil water content reduction on fuel properties, performance and emissions of SI engine fueled with gasoline-fusel oil blends. Renew. Energy 2018, 118, 858-869. [CrossRef]

21. ISO 3679:2015; Determination of Flash Point-Rapid Equilibrium Closed Cup Method. International Organization for Standardization: Geneva, Switzerland, 2015.

22. Rai, A.; Escalona, G.; Betancourt, P.; Sinha, A.K. Hydroprocessing of light cycle oil (LCO) over sulfided NiMo supported on hierarchical mesoporous H-ZSM-5 catalyst. Reaction Kinetics. Mech. Catal. 2018, 125, 1099-1112.

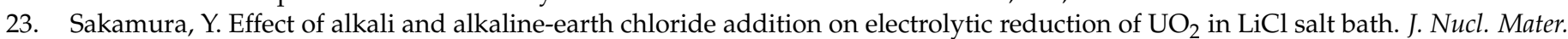
2011, 412, 177-183. [CrossRef]

24. Siles, J.A.; Martin, M.A.; Chica, A.F.; Martin, A. Anaerobic co-digestion of glycerol and wastewater derived from biodiesel manufacturing. Bioresour. Technol. 2010, 101, 6315-6321. [CrossRef]

25. Guan, G.; Kusakabe, K. Synthesis of biodiesel fuel using an electrolysis method. Chem. Eng. J. 2009, 153, 159-163. [CrossRef]

26. Li, H.; Inada, A.; Fujigaya, T.; Nakajima, H.; Sasaki, K.; Ito, K. Effects of operating conditions on performance of high-temperature polymer electrolyte water electrolyzer. J. Power Sources 2016, 318, 192-199. [CrossRef]

27. Shah, A.; Zhang, G.; Hamaker, B.R.; Campanella, O.H. Rheological properties of a soluble self-assembled complex from starch, protein and free fatty acids. J. Food Eng. 2011, 105, 444-452. [CrossRef]

28. Dunn, R.O. Specific Gravity and API gravity of biodiesel and ultra-low-sulfur diesel (ULSD) blends. Trans. Am. Soc. Agric. Biodiesel Eng. 2011, 54, 571-579.

29. Ivanova, E.P.; Nguyen, S.H.; Guo, Y.; Baulin, V.A.; Webb, H.K.; Truong, V.K.; Crawford, R.J. Bactericidal activity of self-assembled palmitic and stearic fatty acid crystals on highly ordered pyrolytic graphite. Acta Biomater. 2017, 59, 148-157. [CrossRef] [PubMed]

30. Kumar, J.; Bansal, A. Application of artificial neural network to predict properties of diesel—biodiesel blends, Kathmandu University Journal of Science. Eng. Technol. 2010, 6, 98-103.

31. Fereidooni, L.; Tahvildari, K.; Mehrpooya, M. Trans-esterification of waste cooking oil with methanol by electrolysis process using KOH. Renew. Energy 2018, 116, 183-193. [CrossRef]

32. Windom, B.C.; Bruno, T.J. Improvements in the measurement of distillation curves. 5. Reduced pressure advanced distillation curve method. Ind. Eng. Chem. Res. 2011, 50, 1115-1126. [CrossRef]

33. Saksono, N.; Junior, A.B.; Anditashafardiani, R.; Muharam, Y. Effect of anode depth in synthesis of biodiesel using the anodic plasma electrolysis method. Chem. Eng. 2019, 10, 491-501. [CrossRef]

34. Folayan, A.J.; Anawe, P.A.L.; Aladejare, A.E.; Ayeni, A.O. Experimental investigation of the effect of fatty acids configuration, chain length, branching and degree of unsaturation on biodiesel fuel properties obtained from lauric oils, high-oleic and high-linoleic vegetable oil biomass. Energy Rep. 2019, 5, 793-806. [CrossRef] 